American Journal of Applied Sciences 8 (6): 508-519, 2011

ISSN 1546-9239

(C) 2011 Science Publications

\title{
Kinetic Optimization of Folic Acid Polymer Conjugates for Drug Targeting
}

\author{
${ }^{1}$ Jacob M. Ngoy, ${ }^{2}$ Sunny E. Iyuke, ${ }^{2,3}$ Clarence S. Yah and ${ }^{1}$ Wilhelm E. Neuse \\ ${ }^{1}$ School of Chemistry, \\ ${ }^{2}$ School of Chemical and Metallurgical Engineering, University of the \\ Witwatersrand, Johannesburg South Africa. Private Bag 3, Wits 2050, \\ ${ }^{3}$ Department of Biochemistry and Toxicology, \\ National Institute for Occupational Health (NIOH), 25 Hospital Street, \\ Constitutional Hill, Johannesburg, South Africa
}

\begin{abstract}
Problem statement: Folic Acid (FA) is an essential, bioavailable water soluble B-complex vitamin that helps in the replication of normal cells. It is obtained from natural sources and it deficiency can leads to oncogenic cells development. Within this frame work in mind, we designed and synthesized a new bioconjugate carrier that can enhance the effectiveness of FA. Approach: The polymeric carrier: Polysucscinimide (PSI) was synthesized via the polycondensation of aspartic acid by attaching 3-(N,N-Dimethylamino) Propylamine (DMP) and 1,3-Plpropylenediamine (PDA) for solubility behavior and reactivity for FA site anchoring. Also the use of an ester 2-(1H-benzotrial-1yl)-1,1,3,3-tetramethylurium Hexafluorophosphate (HBTU) as coupling agent to FA. The bioreversible binding of the water-soluble and biocompatible macromolecular were attested through kinetic studies. The kinetic reactions were investigated through the nuclear resonance $\left(\mathrm{H}^{1} \mathrm{NMR}\right)$ spectra analysis. Results and Conclusion: The $\mathrm{H}^{1} \mathrm{NMR}$ optimization reaction times were found within the range of 120-130 min (80-85\%) as optimum coupling. The yield of the FA occurred within the same time range but with maximum incorporation between $90-100 \%$. The growth of FA incorporation in terms of reaction time resulted to an increase inherent viscosity relative to the decrease of water solubility of the conjugate obtained.
\end{abstract}

Key words: Folic acid, conjugate obtained, inherent viscosity, drug research, drug resistance, sodium hydroxide, glacial acetic acid, aspartic acid, antifolate, enzyme folate, cancer, inefficacious membrane

\section{INTRODUCTION}

Folic acid, or pteroylglutamic acid, consists of a pteridin linked to Para-Aminobenzoic Acid (PABA) and glutamic acid (Fig. 1) responsible for cell development. It is needed for the de novo synthesis of nucleoside thymidine, a DNA nucleoside. According to reports by AL-Sowyan (2009) folic acid can also act as an antioxidants hepatoprotective against paracetamol toxicity. Furthermore, folic acid has also been found to increase survival rate, growth rate and weight gain in vitro culture of Green catfish, hence can be used as to enhance weight and survival rate in animals (Hien and Doolgindachbaporn, 2011).

Folic acid enhances the synthesis of DNA, RNA, thymidylates and proteins, which is part of the folate metabolic pathway (Ströhle et al., 2005; Baran et al., 2006; Edoho et al., 2009) leading to the synthesis of
DNA and normal erythropoiesis. However, folate deficiency, affecting hematopoietic cells and neoplasms, hinders DNA synthesis and cell division. In intestinal cell, FA is mostly reduced to tetrahydrofolate $\left(\mathrm{H}_{4}\right.$ folate), the active form of this vitamin in a two-step reaction, which is catalyzed by the enzyme folate reductase. Inhibitors of this enzyme, like Methotrexate (MTX), act as antifolate. $\mathrm{H}_{4}$ folate functions as a coenzyme, a carrier of various activated one-carbon units in metabolic reactions (WHO, 2009; Faisa et al., 2010). It has been suggested that folate may help prevent cancer, as it is involved in the synthesis, repair and functioning of DNA and a deficiency of folate may result in DNA damage and subsequently cancer formation (Baran et al., 2006). Nowadays, cancer presents one of the most formidable health problems worldwide. More than 10 million people are diagnosed with cancer every year (Health 24-Cancer facts and figures, 2001; Wang et al., 2010; Syamsudin et al.,

Corresponding Author: Sunny E. Iyuke, School of Chemistry, University of the Witwatersrand, Johannesburg, South Africa Private Bag 3, Wits 2050, South Africa 
2010). In South Africa, cancer is the second most common cause of death in the white, coloured and asian population and the third most common cause in the black population group (Neuse, 1998). The inadequate effectiveness of present-day anticancer drugs can be traced to a combination of factors, including poor solubility in aqueous media, inefficacious membrane crossing and cell entry because of structural charge or polarity, lack of cell specificity, short seru'm half-life and most critically, excessive toxicity and a propensity for induction of drug resistance. For this reason, cancer chemotherapy may consist of several drugs in combination for varying lengths of time (Neuse, 2008; Barret and Blanc, 2009; Block and Markovic. 2009).

However, within the framework of macromolecular drug research, the present study aim to address the problem of inefficiency of drug, provide a vehicle for the improvement of pharmacokinetic utilization of FA. Among the various strategies, the formation of bioreversible bond between FA and biocompatible carriers (polymers) were used to avoid the critical pharmacological obstacles. The polymer-FA conjugate resulting from the anchoring step will act as a free-form at the target site. The findings will provide a significant chemotherapeutic module among many emerging biomedical technologies to qualify as an efficacious process to promote cells growth. This include a complete solubility in aqueous media, low systemic toxicity, non-polar, uncharged structure, cell-specific drug action, extended circulation half-life and continuous long-term effectiveness with low probability of emerging drug resistance, thus permitting ongoing treatment at sustained dose level (N'Da, 2006; Pathak et al., 2007). With recognition given to the therapeutic inadequacies associated with most currently administered FA, a special trend in drug research has been observed in recent years which aim at providing pharmacokinetic assistance to a given drug system by the attachment of macromolecular compounds, acting as transport vehicles and drug delivery agents (Sobolev, 2009). This trend has resulted in the development of drug-containing liposomes, microencapsulations and nanoparticles as successful variable delivery systems. One of the most promising macromolecular drug release strategies utilizes water-soluble, biodegradable polymers as carriers of medical agents (O'Rorke et al., 2010). This strategy has matured into a highly successful tool of chemotherapy, circumventing many of the problems associated with the direct administration of the original low-molecular-mass drugs. The polymer-drug conjugation concept as shown in Fig 2-3, pioneered by Caldwell et al. (2006) and significantly refined by O'Rorke et al (2010) is based on a carrier model comprising of a linear polymer chain with subunits bearing water-solubilizing groups and other subunits equipped with functional groups suitable for reversible drug binding.

Other subunits comprise of a homing device, capable of directing the conjugate selectively to the target tissue. The conjugate therefore, represents a prodrug from which the active agent is released into the predestined biological environment by enzymatic or through hydrolytic action (N'Da, 2006; Akram, 2009; Afifi, 2010).

Water solubility is an important requirement for any drug carrier, either polymer or carbon nanotubes intended for used in biomedical field. Therefore, flexible linear polymer are needed because the entropy of the solution will increase thus favouring the dissolution process as well as the intra-or extrachain hydrophilic entities of hydroxyl- and amino-terminals (Guy and Szoka, 2011). These hydrophilic entities are of importance because they are capable of undergoing effective hydration. The ability to incorporate charged species into the polymer also needs hydrosolubility property (Pathak et al., 2007). In addition, the application of Poly(Ethylene Oxide) (PEO) in the therapeutic polymer field has rose tremedously, owing to its numerous properties of solubility in both aqueous and organic media, as well as ease of chemical modification and biocompatibility (Stella et al., 2000; Ahmed and Trathnigg, 2010). Currently Ngoy et al. (2011) found that folic acid bound conjugate to multi walled carbon nanotubes (MWCNTs) had a high hydrophilicity property over conventional conjugates. The modification with MWCNTs made the bioconjugate moiety to have greater versatility in their use.

\section{MATERIALS AND METHODS}

Reagents and solvents: The hydroxyamines and diamines were of analytical grade obtained from Adrich Chemie, Fluka AG, South Africa. These included: D,L aspartic acid, phosphoric acid, 3-dimethylamino-1propylamide (DMP), Diethylenetriamine (DET), 2-2(Ethylenedioxy)-diethylamine (EDDA), 1,3 Diaminopropane (PDA), Dicyclohexylcarbodiimide (DCC), 2-(1H-benzotriazol-1-yl)-1,1,3,3Tetramethyluronium fluorophosphates (HBTU), Triethylamine (TEA), ferrocene, folic acid, methotrexate, sodium hydroxide, chloridric acid, glacial acetic acid, ammonium hydroxide, sulphuric acid and nitric acid. Distilled water was used for all preparative work. The reaction solvent, N,N-Dimethyl for Mamide (DMF), was distilled under reduced pressure, with a fore-runs of around $10 \%$ being discarded and was dried 
over molecular sieves 4Ả. All other solvents, Diethyl ether $\left(\mathrm{Et}_{2} \mathrm{O}\right)$, hexane, acetone and toluene, were of laboratory grade, received from Adrich Chemie, Fluka AG, South Africa.

General methods: ${ }^{1} \mathrm{H}$ NMR spectra were obtained at $300 \mathrm{MHZ}$ and $400 \mathrm{MHZ}$ in $\mathrm{DO}_{2}$ solution. The chemical shifts, $\delta$ in ppm, were referenced against sodium 3(trimethylsily)-2, 2, 3, 3- $\mathrm{d}_{4}$ propionate. The $\mathrm{pH}$ values of the sample in $\mathrm{DO}_{2}$ solution were adjusted to $10-11$ by adding sodium hydroxide in order to eliminate potential protonation effect. Solid-state Infrared (IR) spectra were recorded on potassium bromide $(\mathrm{KBr})$ pellets over the region of $4000-600 \mathrm{~cm}^{-1}$. The attention was focused only on the significant bands.

Dialysis was performed using cellulose membrane spectra (Spectrum Industries, Los Angeles, CA), with a molecular mass cut-off limit of 12000-14000. Distilled water was used for the dialysis phase. Freeze-drying of aqueous polymer and conjugate solutions were performed in a VIRTIS bench-Top 3 Freeze-drier operating at $-30^{\circ} \mathrm{C}$ and $10-15 \mathrm{~Pa}$. The freeze-dried polymers were routinely post-dried in a SARTORIUS GMBH from Germany. Samples for analysis were dried using the Abderhalden apparatus (Thermo Control Infrared desiccators) and calcium chloride was done on a HITACHI 2000 spectrometer, at a scan speed of $400 \mathrm{~nm} / \mathrm{min}$. The flash chromatography was performed using basic alumina as a solid support. The aprotic solvent, N,N-dimethylformamide (DMF), was redistilled and kept over molecular sieves. Using the gel permeation chromatography (GPC) with $2.5 \times 60 \mathrm{~cm}$ column packed with Sepharose 6 gel by the principle of weight average molecular weight $(\mathrm{Mw})$, the polymerFA conjugates were separated from other products.

Preparation of poly- $\alpha \beta$-DL-succinimide: To prepare the poly- $\alpha \beta$-DL-succinimide (Fig. 4), a mixture of D.L. aspartic acid (25g) and $\mathrm{H}_{3} \mathrm{PO}_{4} \quad(12.5 \mathrm{~g})$ was homogenized in a $2 \mathrm{~L}$ round- bottom flask. The flask was then placed in an oil bath at $250^{\circ} \mathrm{C}$. During the polymerization process, the expansion of the mixture was controlled by nitrogen. The reaction was allowed to proceed at $250^{\circ} \mathrm{C}$ until the end of expansion. Thereafter, the temperature was reduced to $190^{\circ} \mathrm{C}$ for another 2 hours. The product was washed with distilled water to obtain a $\mathrm{pH}$ of 6 . The product was left in an oven for 72 hours. The yield of $14.82 \mathrm{~g}$ was dissolved in $60 \mathrm{ml}$ of DMF and stirred overnight $(\mathrm{O} / \mathrm{N})$. The brownish solution obtained was stirred for 1 hour in an ice bath after which $1.73 \mathrm{~g}$ of DCC was added and further stirred for additional 4 hours. The solution was then allowed to continue at room temperature (RT) overnight $(\mathrm{O} / \mathrm{N})$. The solution was centrifuged off to give a clear solution which was precipitated with distilled water. The precipitate was filtered off and was kept in an oven for 48 hours to give a brittle solid which resulted to the yield of $12.75 \mathrm{~g}$.

Synthesis of homopolymers: PSI-DMP (85\%) PDA $(\mathbf{1 5 \%})$ : To a solution of PSI $(2.95 \mathrm{~g} ; 30 \mathrm{mmol})$ in DMF $\left(37 \mathrm{~m} \mathrm{~L}^{-1}\right)$ was added DMP $(2.60 \mathrm{~g} ; 25.5 \mathrm{mmol})$ in DMF $\left(7.5 \mathrm{~m} \mathrm{~L}^{-1}\right)$. The solution was flushed with nitrogen gas and stirred for 24 hours at Room Temperature (RT). With stirring, the resultant solution was added drop wise to PDA $(0.63 \mathrm{~g} ; 8.5 \mathrm{mmol})$ in DMF (8ml) cooled in ice bath. The solution was flushed with nitrogen gas while stirring for 20 hours in an ice bath and for further 5 hours at RT. The solution was then concentrated on the roti-evaporator at $60^{\circ} \mathrm{C}$ to reduce the volume to half. The polymer was then precipitated out with a mixture of diethyl ether-hexane (2:1). The precipitate was washed with hot toluene followed by hot acetone 8 times. The precipitate was then dissolved in distilled water. The $\mathrm{pH}$ solution was adjusted to 7-8 and the solution was dialyzed using 12000 membranes for 96 hours. For the last 6 hours of dialyses, the $\mathrm{pH}$ of the solution was adjusted to $\mathrm{pH} 4$ for 5 min then re-adjusted to 9 with aqueous ammonia to eliminate $\mathrm{N}$ protonation. The product was freeze-dried to obtain the homopolymers of $5.58 \mathrm{~g}$ as yield with 104\% PDA incorporation after $\mathrm{H}^{1} \mathrm{NMR}$ investigation.

Polymer-Folic acid conjugates: PSI-DMP(85\%)PDA(15\%)-FA: The conjugation of folic acid to amine-functionalized polymeric carriers was achieved by using 2-(1H-benzotriazol-1-yl)-1,1,3,3Tetramethyluronium Fluorophosphates (HBTU) coupling agent. The standard procedure for the preparation of all polymer-folic acid conjugates was adopted (Stella et al., 2000). Polymer carrier PSIDMP(85)-PDA(15) (200mg; 0.1 $\mathrm{mmol}$ ) was dissolved in DMF $(7 \mathrm{~mL})$. Folic acid $(100 \mathrm{mg} ; 0.22 \mathrm{mmol})$ was dissolved in DMF $(6 \mathrm{~mL})$ at $50^{\circ} \mathrm{C}$ added to the polymer solution and stirred at RT. During stirring, HBTU (40mg; $0.1 \mathrm{mmol})$ predissolved in DMF $(3 \mathrm{~mL}$ ), was then added drop wise for $20 \mathrm{~min}$, followed by the addition of Triethylamine (TEA) (18.5mg; $0.18 \mathrm{mmol})$. The resulting yellow solution was saturated with $\mathrm{N}_{2}$ and stirred at ambient temperature for different times including 10-130 min to determine the reaction kinetics. The polymeric conjugate obtained after different reaction time was precipitated with $\mathrm{Et}_{2} \mathrm{O}$-hexane (2:1), isolated upon centrifugation and dissolved in $\mathrm{H}_{2} \mathrm{O}$. The $\mathrm{pH}$ was adjusted to 10 using $\mathrm{NaOH}$ and followed by 
size exclusion chromatography on a $2.5 \times 25 \mathrm{~cm}$ column packed with Sephadex G25 and eluted with distilled $\mathrm{H} 2 \mathrm{O}$. The $\mathrm{pH}$ of the solution was readjusted to 7 (glacial acetic acid) to prevent hydrolysis and the solution was dialyzed for 48 hours in Spectre/Por 6 tubing. The $\mathrm{pH}$ of the retentate was readjusted to 4 ( $\mathrm{HCl}$ acid) to regenerate the unconjugated group of FA from its salt. The aqueous solution was stirred at ambient temperature for $5 \mathrm{~min}$, then the $\mathrm{pH}$ re-adjusted to $6(\mathrm{NH} 4 \mathrm{OH})$ and the dialysis in the same tubing was continued for another 8 hours with numerous changes of the aqueous outer phase to complete the removal of inorganic salts. The retentate with $\mathrm{pH} \sim 8$, was freezedried to afford $\mathrm{z}$ mg of yellow, water-soluble conjugate of Polyaspartamide-Folic acid. The ${ }^{1} \mathrm{H}$ NMR spectra data in Table 4.5 were used for the reaction kinetic evaluation.

\section{RESULTS AND DISCUSSION}

Results of Polymer-folic acid conjugates: The reaction kinetics of the polymer-folic acid conjugate was performed with mol ratio of 17/3 PSI-DMP (85)PDA (15)-FA at varying time range of 10 to $130 \mathrm{~min}$. The fractional incorporation of folic acid in the polymeric carrier was calculated through the different ${ }^{1} \mathrm{H}$ NMR Spectra integration as shown in ${ }^{1} \mathrm{H}$ NMR Spectra 1-14. The fraction of incorporation of folic acid and the coupling yield in terms of reaction time were made possible through the base molecular weight (BMW) of the retained polymer, removed polymer and folic acid couplings as shown in Tables 1-2. The different graphs were then plotted in terms of the reaction time as shown in Fig. 5-10.

It is known that with the mole ratio $\mathrm{X} / \mathrm{Y}=17 / 3$, the 3900.89 as Base Molecular Weight (BMW) of simple recur of PSI-DMP (85\%)-PDA (15\%) as carrier, corresponded to $3(441.41)=1324.23$ as BMW of FA. With $\mathrm{x}(\mathrm{mg})$ as coupling yield with the sum of $\mathrm{z}(\mathrm{mg})$ as the quantity of retained polymer carrier in the coupling and $0.0034 \mathrm{zy}(\mathrm{mg})$ as the quantity of FA in the coupling. While $\mathrm{y}$ as $\%$ of FA incorporation calculated from $\mathrm{H}^{1}$ NMR spectra. This led to the following equation:

$$
\mathrm{z}=\frac{\mathrm{x}}{1+0.0034 \mathrm{y}}
$$

Furthermore, Table 2 as shown below was completed with $\mathrm{w}$ being the concentration of folic acid (mg) in the coupling as:

$0.0034 \mathrm{y}$
Using $\mathrm{w}, \mathrm{x}, \mathrm{y}, \mathrm{z}$ and $\mathrm{t}$ (time of reaction) as data from Table 2, it was possible to establish the kinetics equation: Polymer + Folic Acid $\longrightarrow$ Coupling (Fig. 9):

$\mathrm{z}(\mathrm{mg})+\mathrm{w}_{\mathrm{o}}-\mathrm{w}(\mathrm{mg}) \quad \mathrm{x}=\mathrm{z}+\mathrm{w}(\mathrm{mg})$

The adjustment of $\mathrm{w}$ in terms of time gave approximately the following equation:

$w=\frac{t^{2}+790 t}{1500+5 t}$

According to the kinetics equation, Fig. 9 lead to:

$\frac{\mathrm{d}(\mathrm{z}+\mathrm{w})}{\mathrm{dt}}=\mathrm{k}(\mathrm{z}+\mathrm{w})^{\mathrm{n}}$

Note that $\mathrm{k}$ is the rate constant for the reaction and $\mathrm{n}$ the overall order of the reaction. Considering $\mathrm{z}$ constant, the Equation 5 becomes:

$\frac{\mathrm{dw}}{\mathrm{dt}}=\mathrm{k}(\mathrm{z}+\mathrm{w})^{\mathrm{n}}$

After solving iteratively the equation 5 by the use of different data from Table 2, it was found that the reaction was approximately of second order with the average rate constant $\mathrm{k}$ approximately equal to $1.20336 \times 10^{-5} \mathrm{mg}^{-1} \mathrm{~min}^{-1}$.

Therefore on integration, Equation 6 becomes:

$$
\mathrm{t}=\frac{\mathrm{w}}{\mathrm{z}(\mathrm{z}+\mathrm{w}) \mathrm{k}}
$$

Where $x=z+w$ (Fig. 16),

This implies that:

$\mathrm{x}(\mathrm{x}-\mathrm{w})=\frac{\mathrm{w}}{\mathrm{kt}}$

Finally by substitution of equation 5 to 8 gives:

$(1500+5 t) x^{2}-\left(t^{2}+790 t\right) x-8.31 \times 10^{4}(t+790)=0$

This quadratic equation will be useful to assess approximately the yield of coupling at a well-fixed time of reaction. The maximum error to establish these equations was evaluated at $10 \%$.

Results of Polymer-folic acid conjugates: In a chemical reaction, the concentration of reactants decreases with reaction time, while the concentration of 
products increases when the reaction is irreversible. Figure 5 shows that the fraction of incorporation of folic acid in the polymer was increasing with reaction time and the rate of the reaction was also time dependent. Thus, working with min as time, the rate of incorporation ranged from $21.3-34.7 \%$ within $20-60 \mathrm{~min}(0.335 \%$ $\left.\min ^{-1}\right)$. The approximated rate of $0.443 \% \mathrm{~min}^{-1}$ was also found with FA incorporation range of $82.7-96 \%$ within 100-130 min. The rate of 0-21.3\% within 0-20 min was found at $1.065 \% \mathrm{~min}^{-1}$. Furthermore, FA incorporation rate of $34.7-82.7 \%$ was approximately $1.2 \% \mathrm{~min}^{-1}$ within the 60-100 min. Hence, the rate was low within the time range of 0-20 min and 100-130 min and high within the time range of 0-20 min and 60-100 $\mathrm{min}$.

Table 1: Incorporation FA data in terms of time for PSI-DMP (85\%)-PDA (15\%)-FA conjugate reaction

\begin{tabular}{|c|c|c|c|c|}
\hline \multirow{2}{*}{$\begin{array}{l}\text { Reaction time } \\
(\mathrm{min})\end{array}$} & \multirow[t]{2}{*}{${ }^{1}$ HNMR SPECTRA (X) } & \multicolumn{2}{|c|}{$\begin{array}{l}\text { Chemical shift } \delta / p p m ~ n H \text { counted } \\
\text { (nH expected) }\end{array}$} & \multirow[t]{2}{*}{ FA incorporation (\%) } \\
\hline & & $8.7-6.75$ & $1.7-1.6$ & \\
\hline 0 & 1 & $0(15)$ & $40(40)$ & 0 \\
\hline 10 & 2 & $1.2(15)$ & $40(40)$ & 8 \\
\hline 20 & 3 & $3.2(15)$ & $40(40)$ & 21.3 \\
\hline 30 & 4 & $4(15)$ & $40(40)$ & 26.7 \\
\hline 40 & 5 & $4.4(15)$ & $40(40)$ & 29.3 \\
\hline 50 & 6 & $4.8(15)$ & $40(40)$ & 32 \\
\hline 60 & 7 & $5.2(15)$ & $40(40)$ & 34.7 \\
\hline 70 & 8 & $7.2(15)$ & $40(40)$ & 48 \\
\hline 80 & 9 & $8(15)$ & $40(40)$ & 53.3 \\
\hline 90 & 10 & $9.2(15)$ & $40(40)$ & 61.3 \\
\hline 100 & 11 & $12.4(15)$ & $40(40)$ & 82.7 \\
\hline 110 & 12 & $12.8(15)$ & $40(40)$ & 85.3 \\
\hline 120 & 13 & $13.6(15)$ & $40(40)$ & 90.6 \\
\hline 130 & 14 & $14.4(15)$ & $40(40)$ & 96 \\
\hline
\end{tabular}

Table 2: Different values calculated in terms of time from Equation 1 for PSI-DMP (85)-PDA (15)-FA conjugates reaction

\begin{tabular}{|c|c|c|c|c|c|c|c|c|c|c|}
\hline \multirow[t]{2}{*}{$\begin{array}{l}\text { Reaction } \\
\text { time (min) }\end{array}$} & \multirow[t]{2}{*}{$\begin{array}{l}\text { \% FA incorporation } \\
\left({ }^{1} \mathrm{HNMR}\right)\end{array}$} & \multirow{2}{*}{$\begin{array}{l}\text { Yield } \\
\text { Coupling } \\
\mathrm{X} \\
\mathrm{mg}\end{array}$} & \multirow{2}{*}{$\begin{array}{l}\text { Carrier in } \\
\text { coupling } \\
(\%)\end{array}$} & \multicolumn{3}{|l|}{$\begin{array}{l}\text { Removed } \\
\text { carrier }\end{array}$} & \multicolumn{4}{|c|}{ FA in coupling } \\
\hline & & & & $\begin{array}{l}\mathrm{z} \\
\mathrm{mg}\end{array}$ & $(\%)$ & $\mathrm{Mg}$ & $(\%)$ & $\begin{array}{l}\mathrm{w} \\
\mathrm{mg}\end{array}$ & $(\%)$ & $\begin{array}{l}\eta_{\text {inh }} \\
\left(\mathrm{mL}^{-1}\right)\end{array}$ \\
\hline 0 & 0 & 200 & 75.44 & 200 & 100 & 0 & 0 & 0 & 0 & 16.62 \\
\hline 10 & 8 & 203 & 76.57 & 198 & 99 & 2 & 1 & 5.4 & 2.7 & 17.02 \\
\hline 20 & 21.3 & 204 & 76.98 & 190 & 95 & 10 & 5 & 13.8 & 6.8 & 17.95 \\
\hline 30 & 26.7 & 206 & 77.7 & 189 & 94.5 & 11 & 5.5 & 17.1 & 8.3 & 18.83 \\
\hline 40 & 29.3 & 207 & 78.08 & 188 & 94 & 12 & 6 & 18.7 & 9 & 18.34 \\
\hline 50 & 32 & 209 & 78.83 & 188 & 94 & 12 & 6 & 20.5 & 9.8 & 19.06 \\
\hline 60 & 34.7 & 209 & 78.83 & 187 & 93.5 & 13 & 6.5 & 22.1 & 10.6 & 19.27 \\
\hline 70 & 48 & 215 & 81.10. & 185 & 92.5 & 15 & 7.5 & 30.2 & 14 & 19.58 \\
\hline 80 & 53.3 & 219 & 82.6 & 185 & 92.5 & 15 & 7.5 & 33.5 & 15.3 & 19.93 \\
\hline 90 & 61.3 & 223 & 82.6 & 184 & 92 & 16 & 8 & 38.3 & 17.2 & 20.49 \\
\hline 100 & 82.7 & 225 & 84.87 & 176 & 88 & 24 & 12 & 49.5 & 22 & 20.65 \\
\hline 110 & 85.3 & 225 & 84.87 & 174 & 87 & 26 & 13 & 50.5 & 22.4 & 21.58 \\
\hline 120 & 90.6 & 223 & 84.11 & 170 & 85 & 30 & 15 & 52.4 & 23.5 & 21.78 \\
\hline 130 & 96 & 220 & 83.98 & 166 & 83 & 34 & 17 & 54.1 & 24.6 & 22.07 \\
\hline
\end{tabular}

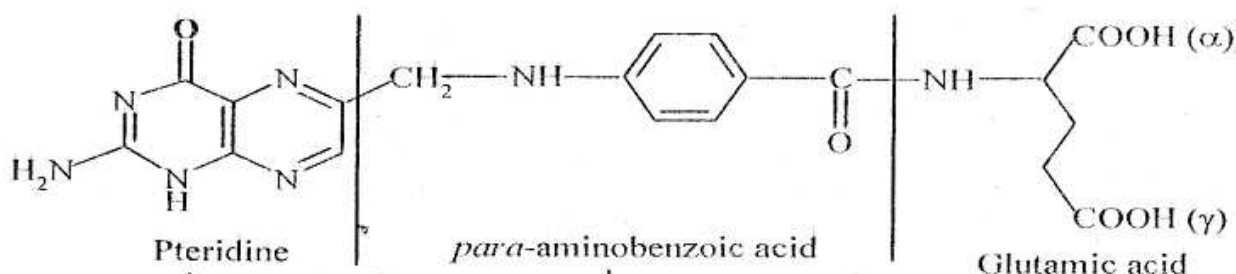

Pteroyl (pteroic acid)

Fig. 1: Structure of folic acid 


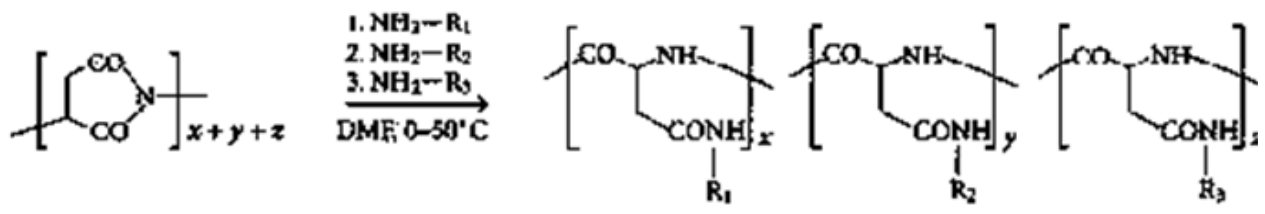

Fig. 2: Amide ring opening process for polyaspartamide

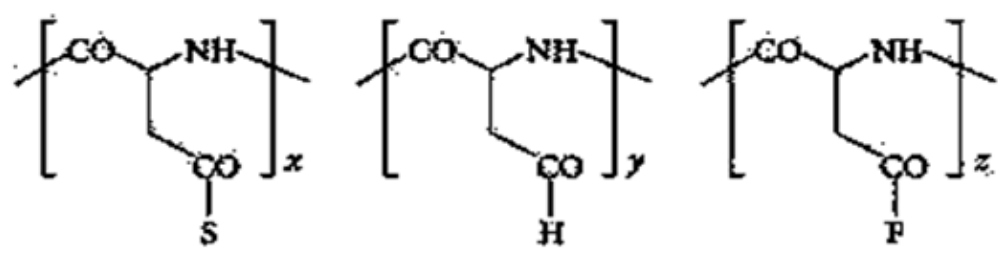

Fig. 3: Substitution of a solubilizing entity $\mathrm{S}$, a homing device $\mathrm{H}$ and a drug-binding functional group $\mathrm{F}$ to polyaspartamide

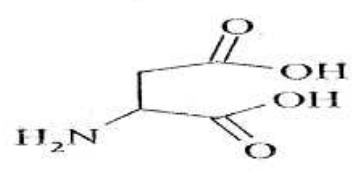

DI-aspartic acid

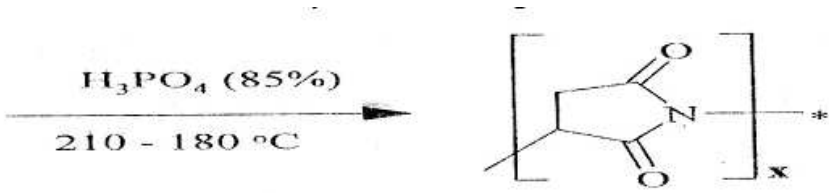

Poly-DL-suceinimide

Fig. 4: Synthesis of Polysuccinimide (PSI)

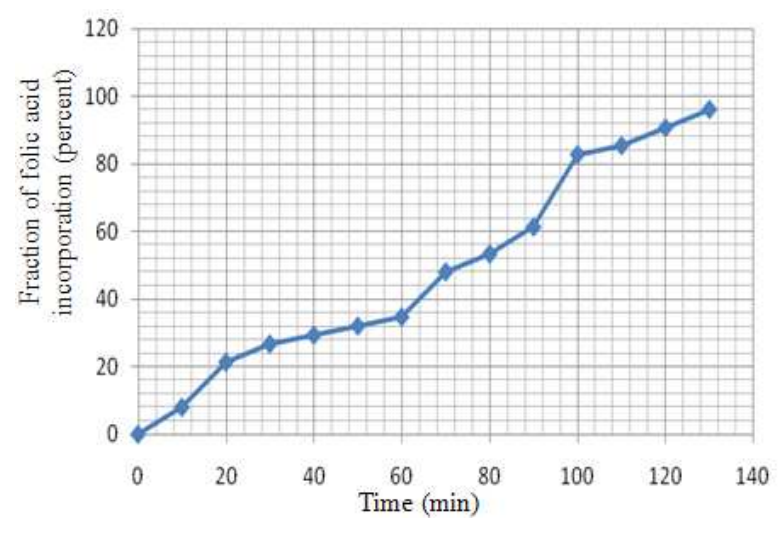

Fig. 5: Fraction FA incorporation versus reaction time (Mol ratio 17/3)

The growth of rate incorporation of folic acid (drug) in the polymer involves the growth of the covalent reversible attachment of the carrier through amide bond formation with folic acid (drug). Thus, the covalent reversible attachment of carrier will keep increasing until it reaches the maximum rate incorporation of folic acid with the polymeric carrier.

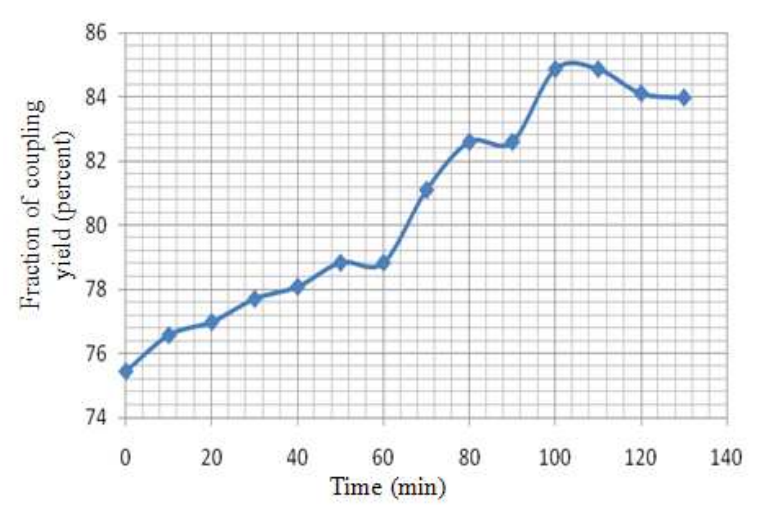

Fig. 6: Fraction of coupling yield versus reaction time (Mol ratio 17/3)

Therefore, the coupling yield will always increase when the covalent reversible attachment is reacting as the cleavage of polymer occurring. This therefore implies that, the reaction between folic acid and the polymeric carrier should result to the growth of the coupling yield in terms of time as the rate of incorporation of folic acid in the polymeric carrier was increasing. This was shown in Fig. 6 where the 
fractional yield was moderately increasing in time range of 0-60 min and became accentuated at maximum time range of 60-100 min, while decreasing at time range of 100-130 min. The varying fractional yield of FA incorporation was due to high molecular weight polymer, which was subject to cleavage during the reaction process. This further, supports the earlier reports by Sharma et al. (2000) that water-soluble polymers, mostly cationic polyelectrolytes, are widely used as flocculants. Furthermore, mineral processing, water clarification and paper manufacturing are some areas where these polymeric flocculants are extensively used (Endo, 2001; Nachtigall et al., 2007; Thwala et al., 2010). According to Endo (2001) the cleavage of the intramolecular bonds may be classified in three cases; (a) the scission can occur in any bonds, (b) the cleavage of the main chain occurs in any bonds, after pendant groups break first, (c) the main chain carbons with the pendant group break in any bonds of the main chain.

The hydrolytic cleavage can occur during the dialysis, however without affecting the final yield because both the chromatography processes observed in the same condition gave the same results at every reaction time.

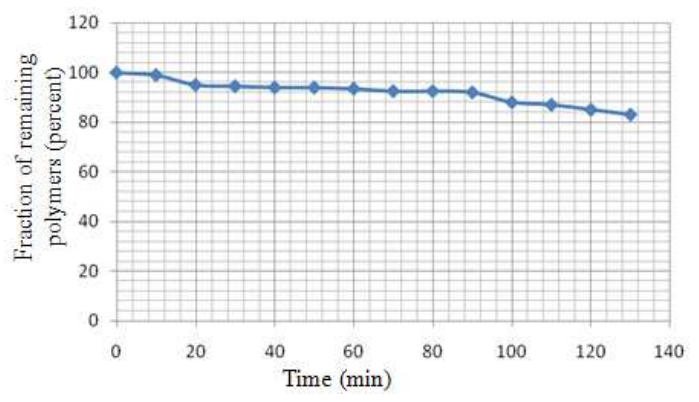

Fig. 7: Fraction of retained polymers versus reaction time (mol ratio 17/3)

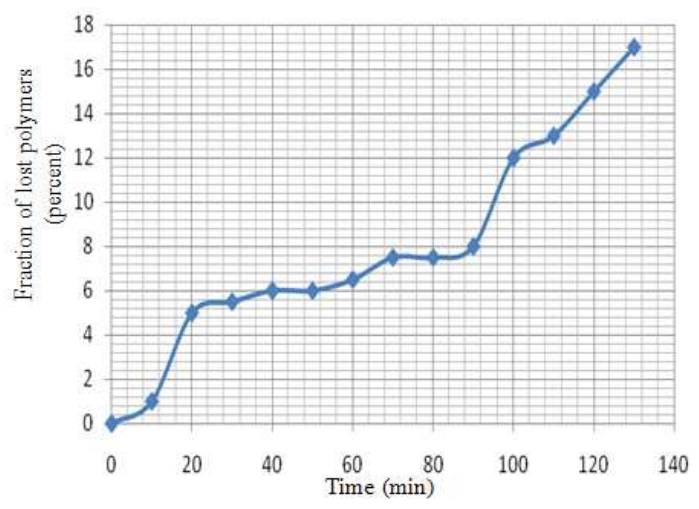

Fig. 8: Fraction of removed polymers versus reaction time (mol ratio 17/3)
The use of 2-(1H-benzotrial-1-yl)-1,1,3,3tetramethylurium Hexafluorophosphate (HBTU) as coupling agent could dispose the polymer to the cleavage of the main chain in any bond. This reduces the length of certain long chains, as well as the molecular weight respectively (Sharma, 2000; Borsig et al., 2008). Therefore, during a chromatography process, all chains with molecular weight under 5000 were removed from the solution and, fewer than 12000 during the dialysis process. It resulted in both a decreased fractional polymeric carrier (Fig. 3) and the growth polymeric carrier (Fig. 4) during the reaction time. This was similar to earlier reports by Nachtigall et al. (2007) that tensile strength decreased with increasing filler loading, polymeric-coupling agent for polypropylene/wood-flour composites.

When Figs. 5-6 were compared, at time range of 60-100 min, it was found that they both had the same pronounced fractional incorporation of FA (34.7$82.7 \%$ ) in an accentuated increasing coupling yield of FA(78.83-84.87\%). Hence, the incorporation of folic acid in the polymeric carrier was a decisive factor to form the coupling yield. Though the remaining polymer fraction was decreasing due to cleavage (Fig. 7), this did not involve more coupling yield. Also the FA incorporation was found growing so fast than the polymer available for the coupling. It was found that the site available for the covalent reversible attachment of the carrier through amide bond formation with FA incorporation was limited to $100 \%$ similar to Nachtigall et al. (2007) reports. Furthermore, to reach the maximum incorporation of folic acid in the polymeric carrier, the reaction was kept running over $100 \mathrm{~min}$, but the maximum coupling yield was found relative at $85 \%$ as shown in Fig. 6. Therefore, taking the reaction to $96 \%$ incorporation of folic acid needed $30 \mathrm{~min}$ more (100-130) within which the yield was decreasing. As the incorporation of folic acid was progressing fast than the cleavage of polymer until $100 \mathrm{~min}$, this caused a rapid reduction of available site capable to receive the folic acid into the polymer. Consequently, in the range of time of 100-130 min the fraction of retained polymer decreased more (Fig. 7) and relatively the fraction of removed polymers increased in the same way (Fig. 8). In the time range of $0-60 \mathrm{~min}$ the fraction of incorporation moderately increased because the activity of the coupling agent in the solution increases with the reaction time, similar trends to Nachtigall et at (2007) and $\mathrm{Su}$ and Huang et al., 2010)_reports. The activity of 
HBTU in the reaction was more effective after $60 \mathrm{~min}$ of reaction due to the fact that the incorporation of folic acid was rapidly increasing within the range reaction time of $60-100 \mathrm{~min}$ where the sites available for reversible covalent attachment were reduced. Because HBTU as coupling agent has to assure the reaction between polymer and drug, the reduction of sites available for the binding after $100 \mathrm{~min}$ of reaction has limited the action of coupling agent. Therefore, the incorporation of folic acid was moderately increasing. In order to avoid more dropping coupling yield due to the polymer cleavage through the over action of HBTU as coupling agent, the reaction was asserted to be stopped within the range min (120-130) where the rate incorporation of folic acid was in the range (90$96 \%$ ) as shown in Figs. 11-23. The percentage $\mathrm{H}^{\mathrm{r}} \mathrm{NMR}$ spectra analyses showed an increasing steadily yield from $10 \mathrm{~min}$ ( $8 \%$ incorporation yield incorporation) with the highest yield incorporation of $96 \%$ at 130 min (Figs. 12-23).

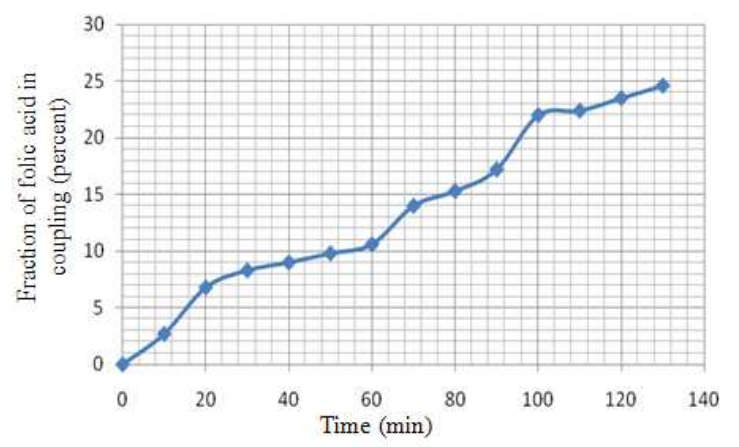

Fig. 9: Fraction of FA in coupling versus reaction time (Mol ratio 17/3)

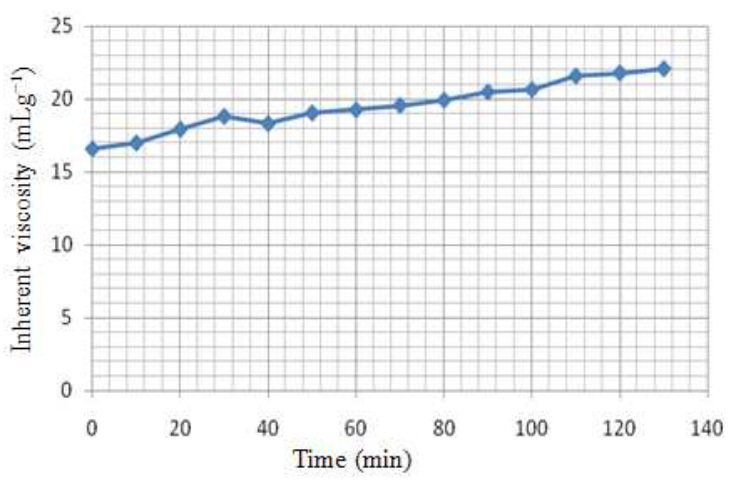

Fig. 10: Inherent viscosity versus reaction time (Mol ratio $17 / 3$ )

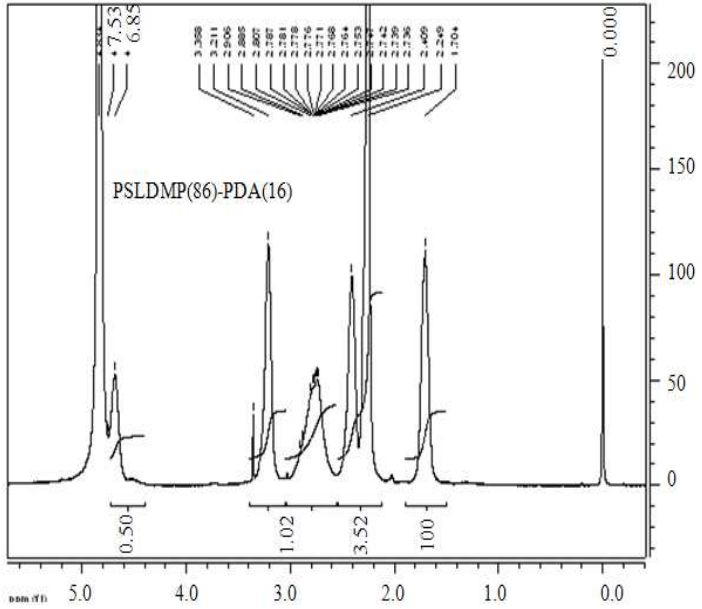

Fig. 11: ${ }^{1} \mathrm{H}$ NMR SPECTRA (1): After 0 minute of reaction ( $0 \%$ FA incorporation)

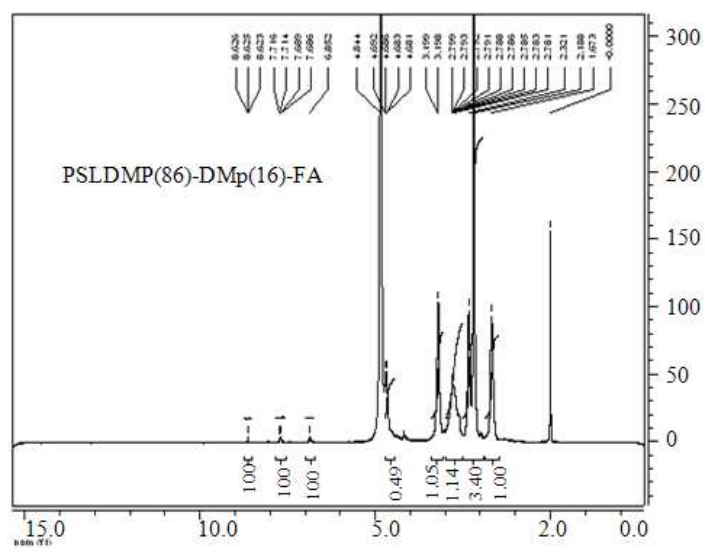

Fig. 12: H NMR SPECTRA (2): After $10 \mathrm{~min}$ of reaction ( $8 \%$ FA incorporation)

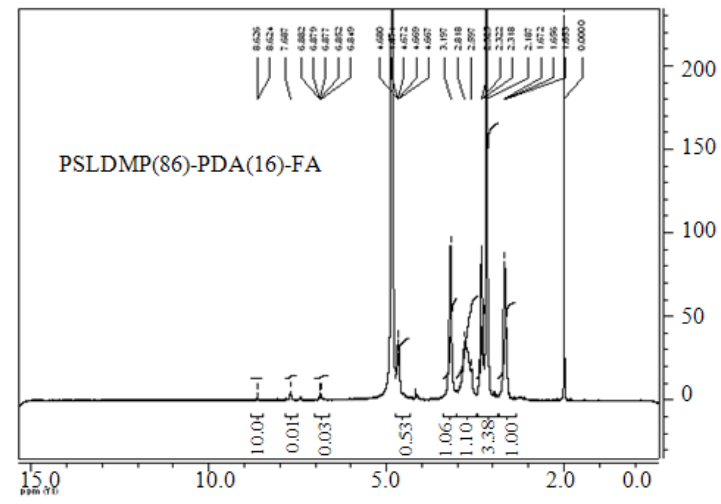

Fig. 13: H NMR SPECTRA (3): After $20 \mathrm{~min}$ of reaction (21.3\% FA incorporation) 
Am. J. Applied Sci., 8 (6): 508-519, 2011

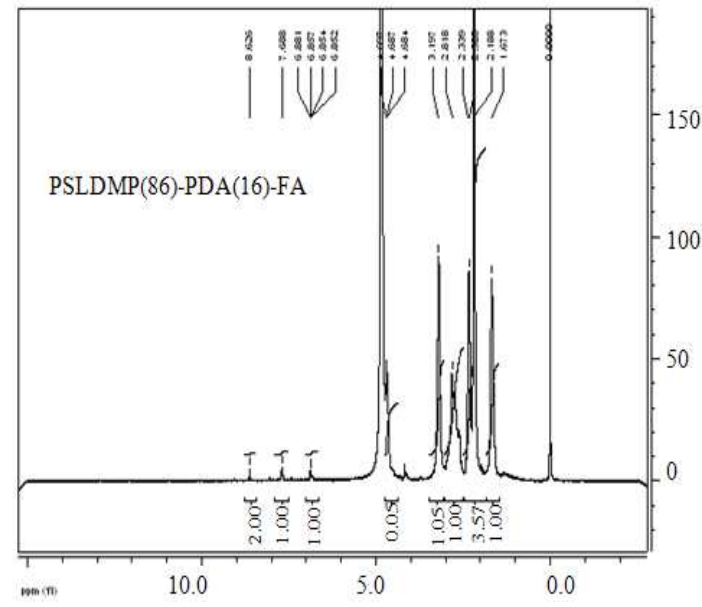

Fig. 14: H NMR SPECTRA (4): After 30 min of reaction (26.7\% FA incorporation)

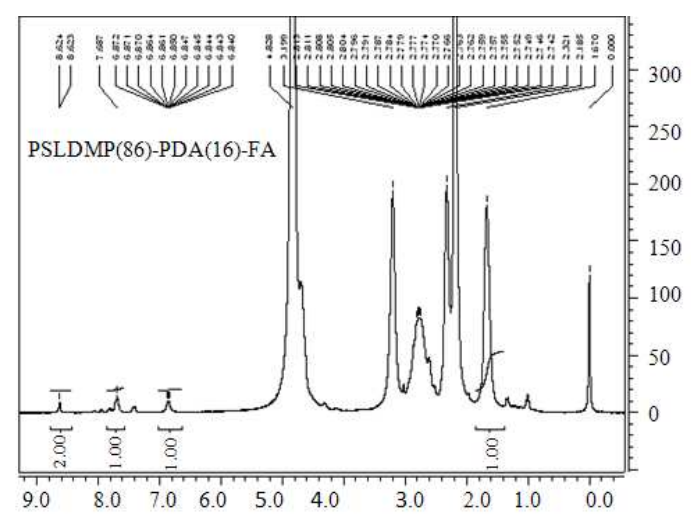

Fig. 15: ${ }^{1} \mathrm{H}$ NMR SPECTRA (5): After 40 min of reaction (29.3\% FA incorporation)

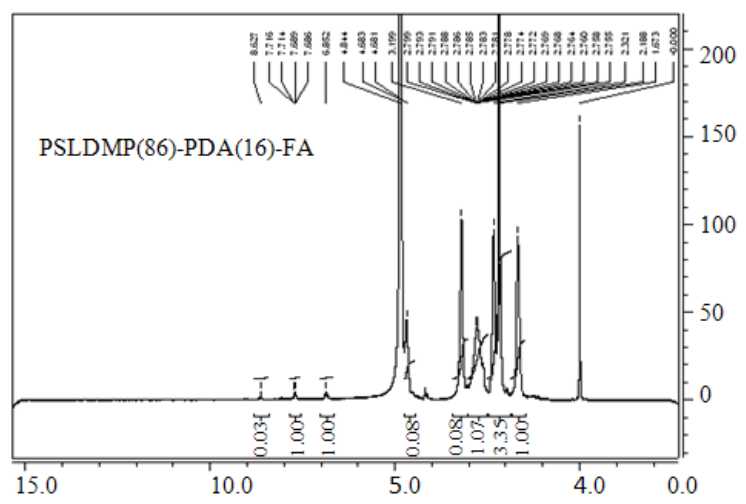

Fig. 16: ${ }^{1} \mathrm{H}$ NMR SPECTRA (6): After $50 \mathrm{~min}$ of reaction (32\% FA incorporation)

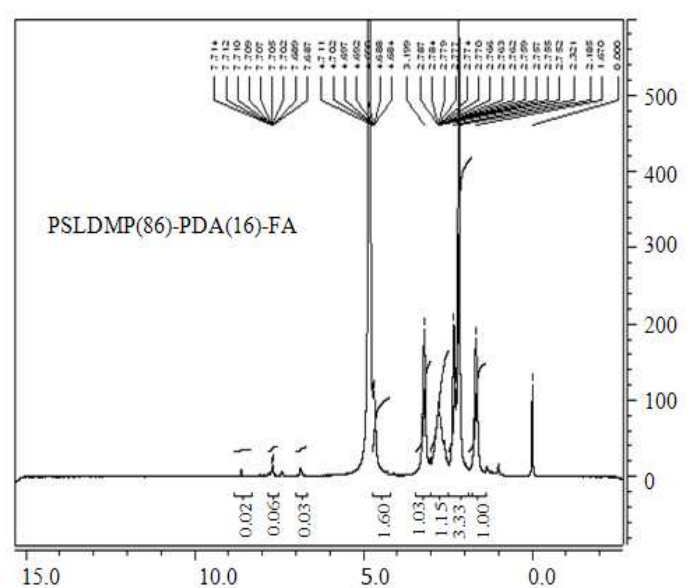

Fig. 17: ${ }^{1} \mathrm{H}$ NMR SPECTRA (7): After $60 \mathrm{~min}$ of reaction (34.7\% FA incorporation)

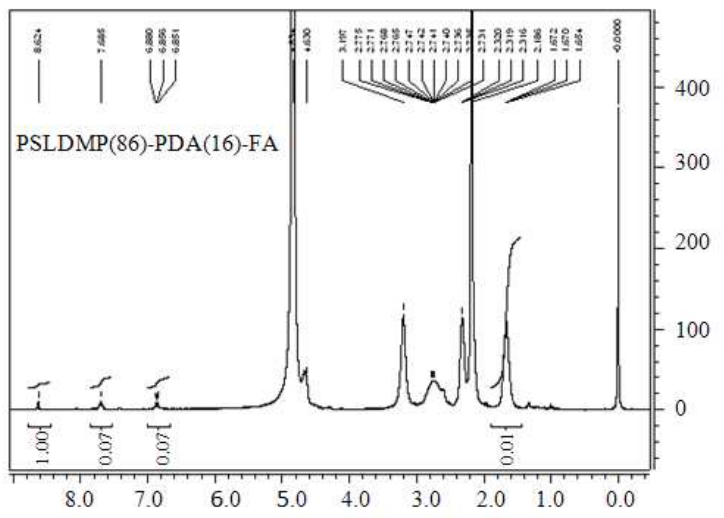

Fig. 18: ${ }^{1} \mathrm{H}$ NMR SPECTRA (8): After $70 \mathrm{~min}$ of reaction) (48\% FA incorporation)

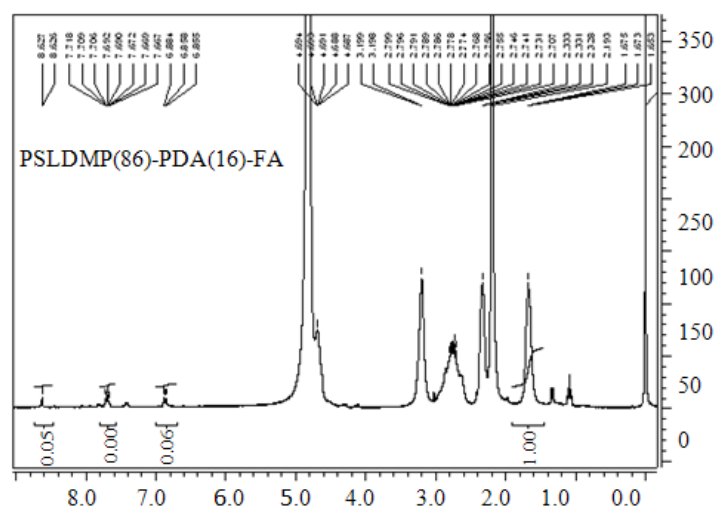

Fig. 19: ${ }^{1} \mathrm{H}$ NMR SPECTRA (9): After $80 \mathrm{~min}$ of reaction) (53.3\% FA incorporation) 


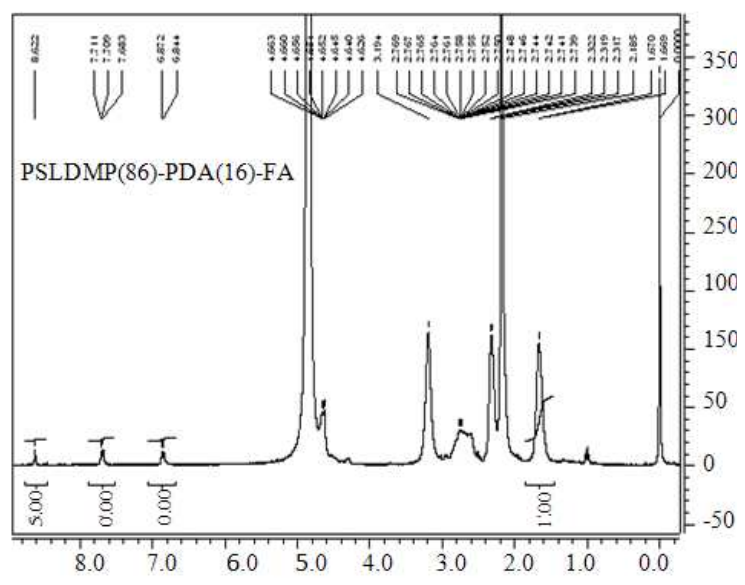

Fig. 20: ${ }^{1} \mathrm{H}$ NMR SPECTRA (10): After $90 \mathrm{~min}$ of reaction (61.3\% FA incorporation)

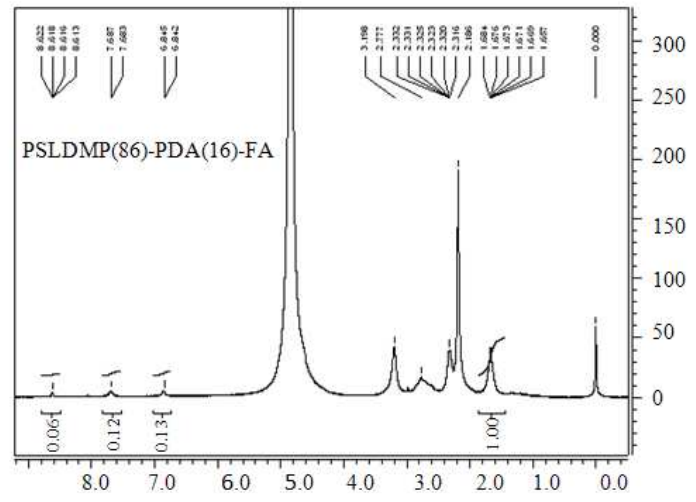

Fig. 21: ${ }^{1} \mathrm{H}$ NMR SPECTRA (11): After $100 \mathrm{~min}$ of reaction) (82.7\% FA incorporation)

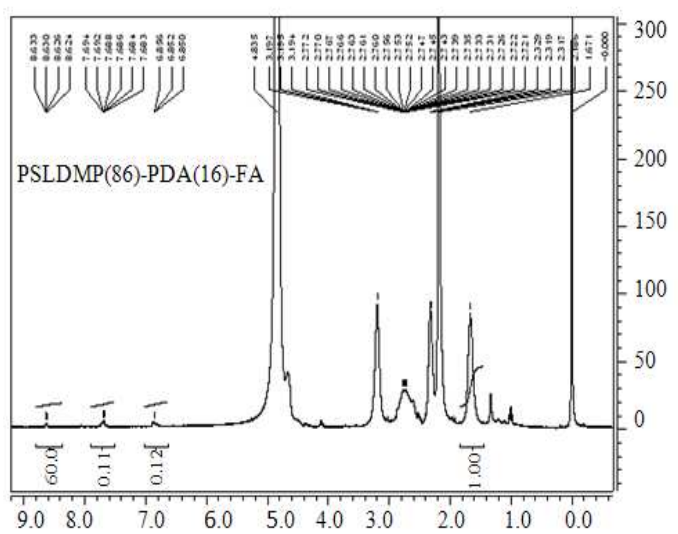

Fig. 22: ${ }^{1} \mathrm{H}$ NMR SPECTRA (12): After $110 \mathrm{~min}$ of reaction (85.3\% FA incorporation)

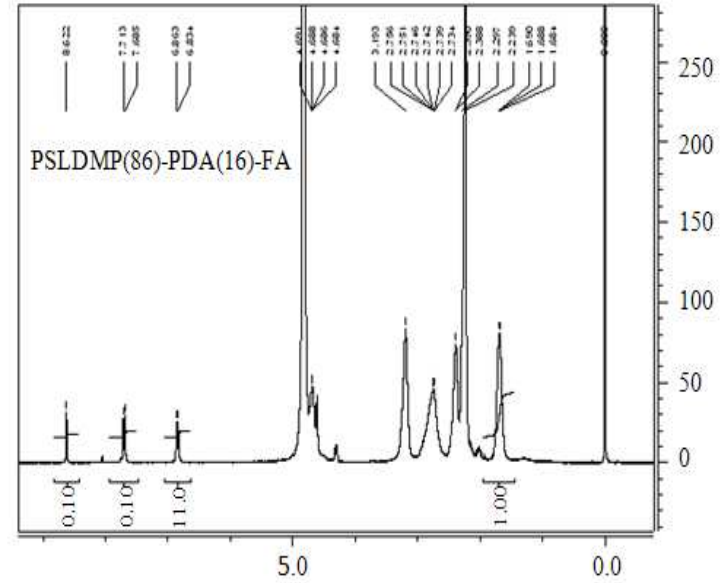

Fig. 23: ${ }^{1} \mathrm{H}$ NMR SPECTRA (13): After $120 \mathrm{~min}$ of reaction (90.6\% FA incorporation)

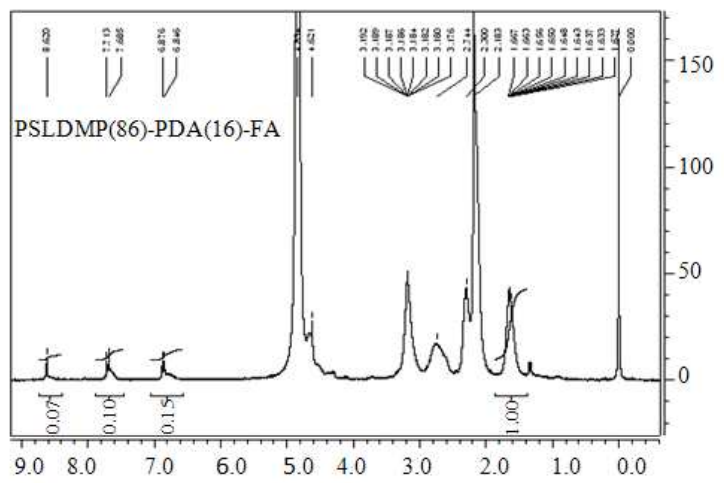

Fig. 24: ${ }^{1} \mathrm{H}$ NMR SPECTRA (14): After $130 \mathrm{~min}$ of reaction) (96\% FA incorporation)

The inherent viscosity was increasing with the reaction time (Fig. 10) because of the incorporation of folic acid (drug) while challenging the solubility of the carrier, which could make the compound more viscous. Spectra evaluation:

\section{CONCLUSION}

The current research was undertaken to investigate the formation of biofissionable amide in polymer bound folic acid. A variety of polymers were chosen to be conjugated to folic acid. This was made possible by using an ester, 2-(1H-benzotrial-1-yl)-1,1,3,3tetramethylurium Hexafluorophosphate (HBTU), as coupling agent. The challenge is that the long chain can be subjected to cleavage during the reaction. The kinetic study was found necessary to optimize the time of reaction for a minimum cleavage with a maximum 
incorporation of folic acid giving at optimum yield. Thus, the time of reaction was set within the range of 120-130 min. In this time, the incorporation of folic acid varied between $90 \%$ and $104 \%$ for a yield within the range of $80-85 \%$.

\section{ACKNOWLEDGEMENT}

The researchers acknowledge the financial support from the National Research Foundation (NRF) under a South Africa-China collaborative research grant, NRF Focus Area, NRF Nanotechnology flagship programme, DST/NRF Centre of Excellence. The student bursaries provided by the Wits University are much appreciated.

\section{REFERENCES}

Afifi, M.M.E.2010. Effect of camel's milk on cisplatininduced nephrotoxicity in swiss albino mice. Am. J. Biochem. Biotechnol., 6: 141-147. DOI: 10.3844/ajbbsp.2010.141.147

Ahmed, H. and B. Trathnigg, 2010. Characterization of PEG in monomethyl ethers of PEG by 2-D LC. J. Separation Sci., 33: 1448-1453. DOI: $10.1002 /$ jssc. 200900847

Akram, W., 2009. Screening of breast mass in iraqi females: Al-Kindy hospital breast clinic. Am. J. Infect. Dis., 5: 320-323. DOI: 10.3844/ajidsp.2009.320.323

AL-Sowyan, N.S., 2009. Efficacy and safety of folic acid during toxic hepatitis induced by acute overdose of paracetamol. Int. J. Pharmacol., 5: 208-214. DOI: 10.3923/ijp.2009.208.214

Baran, O.P., P.Kervancioglu, M. Akkus and Y. Nergiz. 2006. Ultrastructural investigation of the protective role of folic acid and vitamin $\mathrm{E}$ against toxic effects of valproic acid on maternal liver tissue during period of gestation. Saudi Med. J., 27: 4079. PMID: 16532111

Barret, J and K.L. Blanc. 2009. Cancer chemotherapy and immune regulation. Am. J. Immunol., 5: 8-16. DOI: $10.3844 /$ ajisp.2009.8.16

Block, M. S. and S. N.Markovic. 2009. The tumor/immune interface: Clinical evidence of cancer immunosurveillance, immunoediting and immunosubversion. Am. J. Immunol., 5: 29-49. DOI: 10.3844/ajisp.2009.29.49

Borsig, E., M. van Duin, A.D. Gotsis and F. Picchioni. 2008. Long chain branching on linear polypropylene by solid state reactions. European Polymer J., 44: 200-212. DOI:10.1016/j.eurpolymj.2007.10.008
Caldwell, G., M.G. Meirim, D.D. N'Da and E.W. Neuse, 2006. Carrier-bound methotrexate. II. Water-soluble polyaspartamide methotrexate conjugates with amide links in polymer-drug spacer. J. Applied Polymer Sci., 100: 3415-3424. DOI: 10.1002/app.21531

Edoho, U.A., J. Edoho, O. Eseyin and E.I. Etim, 2009. Effect of Artemisin with folic acid on the activities of aspartate amino transferase, alanine amino transferase and alkaline phosphatase in rat. Asian J. Biochem., 4: 55-59. DOI: 10.3923/ajb.2009.55.59

Endo, K., 2001. Prediction of Cleavage Sites for Polymers in SIMS by MO Calculations. J. Mass Spectrom Soc. Jpn., 49: 135-143. 01A0788297

Faisal I. Mohammad, Sally Awawdeh, A. Saleh and N.A. Bashir, 2010. Total level of serum homocysteine in males and females with coronary heart disease of different age groups. Am. J. Biochem. Biotechnol., 6: 116-119. DOI: 10.3844/ajbbsp.2010.116.119

Guy, R.H. and F.C. Szoka Jr., 2011. Perturbation of solute transport at a liquid-liquid interface by Polyethylene Glycol (PEG): implications for PEGinduced biomembrane fusion. Phys. Chem. Phys., DOI: $10.1039 / \mathrm{C} 0 \mathrm{CP} 02305 \mathrm{~A}$

Health 24-Cancer facts and figures, 2001. Type of Cancer prevalent in South Africa.

Hien, D.V. and S. Doolgindachbaporn, 2011. Effect of niacin and folic acid in feed rations on growth and live weights of green catfish (Mystus nemurus Valenciennes 1840). Pak. J. Biol. Sci., 14: 64-68. DOI: $10.3923 /$ pjbs.2011.64.68

N'Da, D.D., 2006. Synthesis of methotrexate and Ferrocene conjugates as potential anticancer agents. PhD thesis, Faculty of Science, University of the Witwatersrand, South Africa.

Nachtigall, M.B.S., G.S. Cerveira and S.M.L. Rosa, 2007. New polymeric-coupling agent for polypropylene/wood-flour composites. Polymer Testing, 26: 619-62. DOI:10.1016/j.polymertesting.2007.03.007

Nachtigall, M.B.S., G.S. Cerveira and S.M.L. Rosa, 2007. New polymeric-coupling agent for polypropylene/wood-flour composites. Polymer Testing, 26: 619-62. DOI:10.1016/j.polymertesting.2007.03.007

Neuse, E.W., 1998. Carrier-bound platinum and iron compounds with carcinostatic properties. Polym. Adv. Technol., 9: 786 \pm 793. DOI: 10.1002/(SICI)1099-1581(1998100) 
Neuse, E.W., 2008. Synthetic Polymers as DrugDelivery Vehicles in Medicine, Met Based Drugs. 2008 : 469531. PMCID: PMC2386871

Ngoy, J.M., S.E. Iyuke, W. E. Neuse and C. S. Yah. 2011. Covalent Functionalization for multi-Walled Carbon Nanotube (f-MWCNT) -Folic Acid bound bioconjugate. Journal of Applied Sciences. DOI : $10.3923 /$ jas.2011

O'Rorke, S., M. Keeney and A. Pandit. 2010.Non-viral polyplexes: Scaffold mediated delivery for gene therapy. Prog. Polymer Sci., 35: 441-458. DOI:10.1016/J.PROGPOLYMSCI.2010.01.005

Pathak, P. and V.K. Katiyar. 2007. Multi-functional nanoparticles and their role in cancer drug delivery-a review. J. Nanotechnol. Online. 3: 1-7. DOI: 10.2240/azojono0114

Sharma, B.R., N.C. Dhuldhoya and U.C. Merchant. 2000. Flocculants-an ecofriendly. Appro J Polymers Environ., 14: 195-202. DOI: 10.1007/s10924-006-0011-x

Sobolev, A.S., 2009. Novel modular transporters delivering anticancer drugs and foreign DNA to the nuclei of target cancer cells. J. BUON. 14(Suppl 1): S33-S42. PMCID: PMC2834187

Stella, B., A.S. Peracchia, le D. Desmae, J. Hoebeke, M. Renoir, J. D'angelo, L. Cattel and P. Couvreur, 2000. Design of Folic Acid-Conjugated Nanoparticles for Drug Targeting. J. Pharma. Sci., 89: 1452-1464. DOI: 10.1002/1520-6017(200011)
Ströhle, A., M. Wolters and A. Hahn. 2005. Folic acid and colorectal cancer prevention: Molecular mechanisms and epidemiological evidence (Review). Int. J. Oncology, 26: 1449-1464. http://www.spandidospublications.com/ijo/26/6/1449

Su, F.H. and H.X. Huang. 2010. Rheology and melt strength of long chain branching polypropylene prepared by reactive extrusion with various peroxides. Polymer Engin. Sci., 50: 342-351. DOI: $10.1002 /$ pen. 21544

Syamsudin, P. Simanjuntak, R. Djamil and L. Heffen, 2010. Apoptosis of human breast cancer cells induced by ethylacetate extracts of propolis. Am. J. Biochem. Biotechnol., 6: 84-88. DOI: 10.3844/ajbbsp.2010.84.88

Thwala, J.M., J.W. Goodwin and P.D. Mills, 2010. Viscoelastic and shear viscosity studies of colloidal silica particles dispersed in Monoethylene Glycol (MEG), Diethylene Glycol (DEG) and dodecane stabilized by dodecyl hexaethylene glycol monoether $\left(\mathrm{C}_{12} \mathrm{E}_{6}\right)$. Langmuir, 24: 12858-12866. DOI: $10.1021 / \mathrm{la} 8026754$

Wang, R., G. Han, J. Wang, G. Chen and R. Xu et al., 2010. Foxp3-mediated immunity of human pancreatic cancer cell line PANC-1. Am. J. Immunol., $\quad$ 5: $101-107 . \quad$ DOI: 10.3844/ajisp.2009.101.107

World Health Organization (WHO). Fact sheet No 297, February 2009. 